\title{
Wireless Video Sharing Secara Real Time Menggunakan Streaming Engine
}

\author{
Suhe rman $^{1}$, Abd. Rabi, ${ }^{2}$, Anggraini Pus pita Sari ${ }^{3}$ \\ ${ }^{1}$ Program Studi Teknik Elektro, Fakultas Teknik, Universitas Merdeka Malang \\ ${ }^{2,3}$ Dosen Teknik Elektro, Fakultas Teknik, Universitas Merdeka Malang \\ e-mail : suhermanmco@gmail.com
}

\begin{abstract}
ABSTRAK
Berkembangnya era dan teknologi khususnya di bidang telekomunikasi sangat pesat, kebutuhan akan media telekomunikasi seperti penyiaran video secara real time merupakan prioritas utama dalam proses belajar mengajar, pengumuman berita dan sebagainya, komunikasi nirkabel yang efisien dan menghemat waktu. dalam penggunaannya Penelitian ini menggunakan kamera pada smartphone sebagai media input data yang dapat digunakan untuk pengguna dan menggunakan wifi (wire less Fidelity) sebagai komunikasi nirkabel, media transfer dan data trasmisi, dan penggunaan pada notebook sebagai media pengolahan data berupa video yang akan ditampilkan. pada monitor secara real time sebagai media output data yang telah di input oleh pengguna melalui smartphone kamera dalam bentuk video dengan berbagai format resolusi video mulai dari 480, 680 dan 720, dan hasil test data keluaran berupa video yang dengan menggunakan variabel delay, throughput dan packet loss, hasil dari pengujian variabel dengan menggunakan format video 480, 680 dan 720 menghasilkan rata-rata delay tercepat adalah $0.003738977 \mathrm{~ms}$ dan terlama adalah $0.00529923 \mathrm{~ms}$, pada troughput tertinggi menghasilkan rata-rata $1.179 \mathrm{Mbps}$ dan terendah $0.128 \mathrm{Mbps}$, pada packet loss tertinggi $17.6 \%$ dan terendah $6.54 \%$.
\end{abstract}

\section{Kata Kunci: Video, Real time, WLAN, Notebook}

\section{PENDAHULUAN}

Teknologi yang semakin berkembang pada bidang ilmu pengetahuan telekomunikasi yang sedemikian pesat telah membawa dampak yang cukup besar terhadap kehidupan manusia untuk mempelajari dan mengembangkan pengetahuanya. Berkembangnya teknologi digital saat ini sangatlah menjamur contohnya penggunaan smartphone, computer, dan gadget untuk kegiatan sehari-hari seperti menelpon, mengirim SMS, belajar, be lanja, perbankan,

\section{Latar be lakang}

akses media social dan dapat terhubung langsung dengan internet. Adanya pemanfaatan teknologi inilah yang memudahkan manusia untuk menyelesaikan pekerjaan, menghemat waktu dan tenaga dalam penggunaanya, hal itu diharapkan dapat memenuhi kebutuhan hidup manusia dengan aman dan nyaman.

Seiring berkembangnya teknologi pada bidang telekomunikasi saat ini kebutuhan akan media penyiaran video secara realtime pada saat ini sangat dibutuhkan dalam berbagai hal seperti dalam proses belajar mengajar, berita, pengumuman dan lain-lain, penggunaan wifi (wireless Fidelity) masih menjadi pilihan sampai saat ini untuk melakukannya penyiaran video secara realtime, akan tetapi penggunaan pada camera portable masih menjadi pilihan di beberapa kalangan, tetapi penggunaan camera portable untuk melakukan peyiaran secara realtime masih terbilang kurang efektif dalam penggunaanya, dikarenakan penginputan pada media yang akan diambil oleh user sangatlah terbatas serta ruang gerak user itu sendiri (keleluasaan) apabila menggunakan camera portable. Oleh karena itu dibutuhkan sistem dan hardware yang dapat digunakan secara fleksibel dalam penggunaanya. Berdasarkan permasalahan tersebut, penulis membuat tugas akhir yang berjudul "Wireless Video Sharing secara Real Time Menggunakan Streaming Engine ". bertujuan memanfaatkan camera pada smartphone sebagai media input data yang dapat digunakan dimana saja tanpa ada batas ruang gerak pada user itu sendiri (keleluasaan), serta menggunakan wifi (wire less Fide lity) sebagai komunikasi nirkabel, media transfer dan trasmisi data, serta mengembangkan seberapa besar penggunaan pada Notebook sebagai media pengolah data berupa video yang akan ditampilkan pada monitor secara realtime sebagai media hasil output data yang telah diinput oleh user melalui camera smartphone. 


\section{Rumusan Mas alah}

Masalah yang di hadapi berdasarkan latar belakang, dapat dirumuskan permasalahan sebagai berikut: Bagaimana merancang pengiriman video realtime dengan menggunakan camera smartphone sebagai input dan Notebook sebagai media pengolah data berupa video.

\section{Tujuan Pene litian}

Tujuan utama dari penelitian tugas akhir ini adalah memahami dan mempelajari prinsip kerja dari pengiriman data berupa video secara realtime menggunakan wifi (wireless Fidelity) sebagai komunikasi wireless, media transfer dan trasmisi data berupa video yang akan ditampilkan secara realtime dan media hasil output data yang telah diinput oleh user melalui camera smartphone.

\section{Re altime}

\section{METODOLOGI}

Realtime adalah pemrosesan yang sangat cepat pada pengontrolan, perekaman data, sehinga yang dihasilkan dapat diterima dalam waktu yang relatif sama.Perbedaan pada sistem online adalah satuan waktu yang digunakan realtime biasanya seperseratus atau seperseribu detik sedangkan online masih dalah skala detik atau bahkan kadang beberapa menit [1]. Mekanisme dari pengontrolan, perekaman data, pemrosesan yang cepat sehinga output yang dihasilkan dapat diterima dalam waktu jangka yang relatif sama. Perbedaan dengan sistem online adalah satuan waktu yang digunakan realtime biasanya seperseratus atau seperseribu detik sedangkan online masih dalah skala detik atau bahkan kadang beberapa menit. Perbedaan lainnya, online biasanya hanya berinteraksi dengan pemakai, sedangkan realtime berinteraksi langsung dengan pemakai dan lingkungan yang dipetakan.

\section{Android}

Android merupakan sebuah sistem operasi pada handphone yang bersifat terbuka dan berbasis pada sistem operasi Linux. Android bisa digunakan oleh setiap orang yang ingin menggunakannya pada perangkat mereka. Android menyediakan platform terbuka bagi para pengembang untuk menciptakan aplikasi mereka sendiri yang akan digunakan untuk bermacam peranti bergerak. Awalnya, Google Inc. membeli Android Inc., pendatang baru yang membuat peranti lunak untuk ponsel. Kemudian untuk mengembangkan Android, dibentuklah Open Handset Alliance, konsorsium dari 34 perusahaan peranti keras, peranti lunak, dan telekomunikasi, termasuk Google, HTC, Intel, Motorola, Qualcomm, T-Mobile, dan Nvidia [4].

\section{Streaming}

Streaming merupakan istilah sebuah file video maupun audio yang dapat dimainkan tanpa terlebih dahulu dilakukan pengunduhan untuk file tersebut. Streaming juga dapat diartikan teknik yang digunakan untuk melakukan transfer data sehingga dapat diproses secara tetap dan berlanjut [3].

\section{Stre aming Engine}

Streaming engine adalah sebuah rana yang dipergunakan untuk melakukan berbagai kegiatan yang mencagkup dari pengolahan data berupa audio, picture dan video yang nanntinya akan diolah secara realtime. Streaming engine mempunyai keunggulan dapat men-deliver video streaming dengan banyak format, dari satu format video input saja, sehingga lebih efisien. Beberapa tipe format keluaran yang dihasilkan oleh streaming engine adalah HLS, RTSP, RTMP, Smooth Streaming, dan lain-lainnya, Smooth Streaming, dan la in-la innya. Real Time Messaging Protocol (RTMP) adalah protokol yang dikembangkan oleh Adobe Systems aplikasi lapisan proprietary, Penerapan android streaming yang dimaksud yaitu menggunakan protokol Real Time Messaging Protocol (RTMP) dan Real Time Streaming Protocol (RTSP) pada proses streaming yang berlangsung. Server RTSP dibangun untuk berinteraksi dengan perangkat android stream video dan aplikasi. Adanya RTMP dan RTSP membuat aplikasi dapat dibangun di smartphone android sehingga dapat membagi informasi ke user. [10]. Dengan demikian video streaming keluaran dari streaming engine dapat ditonton dari berbagai tipe perangkat user misalnya $\mathrm{PC} /$ laptop, Apple iPad/iPhone, smartphone Android, Blackberry, Windows Phone, bahkan set-top box. [11]. 


\section{Arsitektur Stre aming Engine}

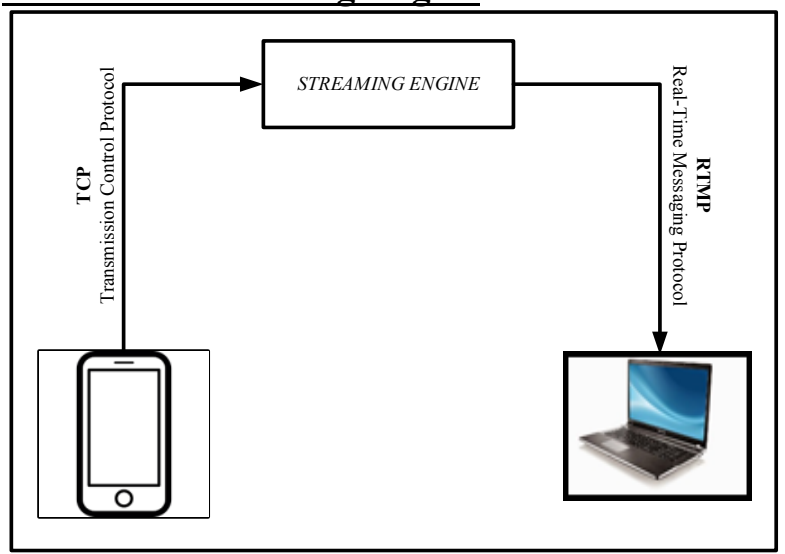

Gambar 1 Arsitektur Stre aming Engine

Arsitektur sistem android Streaming yang menjelaskan bahwa saat android mulai menjalankan program, camera mulai menggambil video. Video dikirim ke Streaming Engine media engine sebagai mesin streaming yang dapat melakukan streaming video dan Streaming engine media engine juga bertindak sebagai kerangka streaming server yang menerima video dari perangkat android menggunakan protokol RTSP dengan menggunakan port 1935. Setelah stream data diterima oleh media engine, data stream akan di-decode dan ditampilkan ke webpage menggunakan protokol RTMP [12]. Arsitektur dari Streaming engine.

\section{Delay}

Delay merupakan lamanya waktu yang dibutuhkan oleh data/informasi untuk sampai ke tempat tujuan data/informasi tersebut dikirim [16]. Delay dalam suatu jaringan dapat dijadikan acuan dalam menilai kemampuan dan kualitas penstramisian data. Delay diperoleh dari selisi waktu kirim antar satu paket dengan paket lainnya yang direprensentasikan dalam satuan second.

Rumus untuk menghitung nilai de lay adalah :

$$
\text { Delay }=\frac{\text { Total Delay }}{\text { Total Paket yang diterima }}
$$

\section{Troughput}

Throughput merupakan jumlah bit yang berhasil dikirim pada suatu jaringan. Throughput adalah sebuah parameter yang menunjukkan dari kinerja suatu komunikasi data, yaitu menunjukkan jumlah data yang diterima dengan benar pada penerima setelah melewati media transmisi pada data link layer dari client to client [17].

$$
\text { Throughput }=\frac{\text { data yang dikirim }}{\text { waktu pengiriman }}
$$

\section{Packetloss}

Kegagalan pada saat transmisi sebuah paket yang mencapai tujuannya dapat didefinisikan sebagai Packetloss, paket data yang hilang saat dikirimkan host sumber adalah PacketLoss. hal tersebut dapat terjadi dikarenakan dalam perangkat jaringan tumbukan antar paket, layer fisik seperti degradasi sinyal, hingga pada layer aplikasi seperti kesalahan software [18].

$$
\begin{aligned}
& \text { paket Loss } \\
& =\frac{(\text { Paket total tercapture-Paket Terkirim })}{\text { Paket total tercapture }} \times 100 \%
\end{aligned}
$$

\section{Flowchart Smartphone}

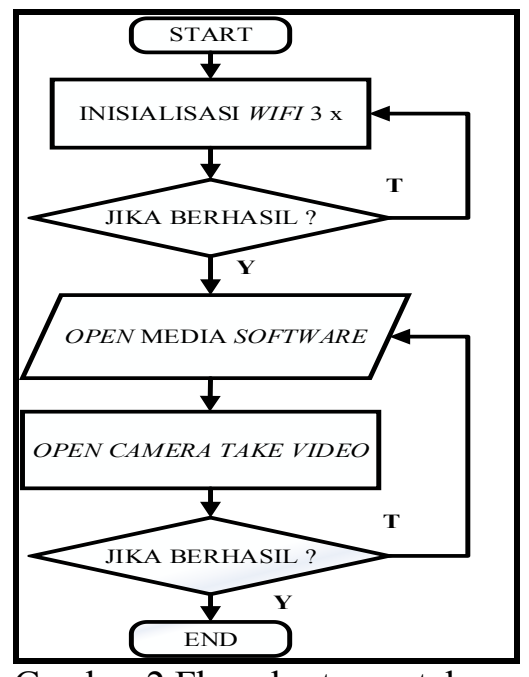

Gambar 2 Flowchart smartphone

Flowchart Notebook/PC

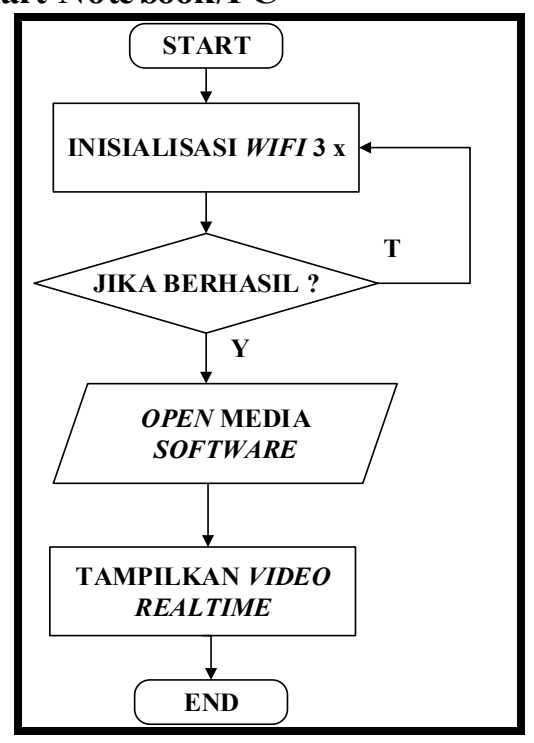

Gambar 3 Flowchart Notebook/PC 


\section{III.HASIL DAN PEMBAHASAN}

\section{Rekondisi pada jaringan Wifi}

Rekondisi pada jaringan WIFI adalah tahap pertama yang bertujuan seberapa besar kesiapan software untuk melakukan tahap connect pada WIFI untuk melakukan komunikasi nirkabel. Hasil dari pengujian rekondisi pada jaringan WIFI.

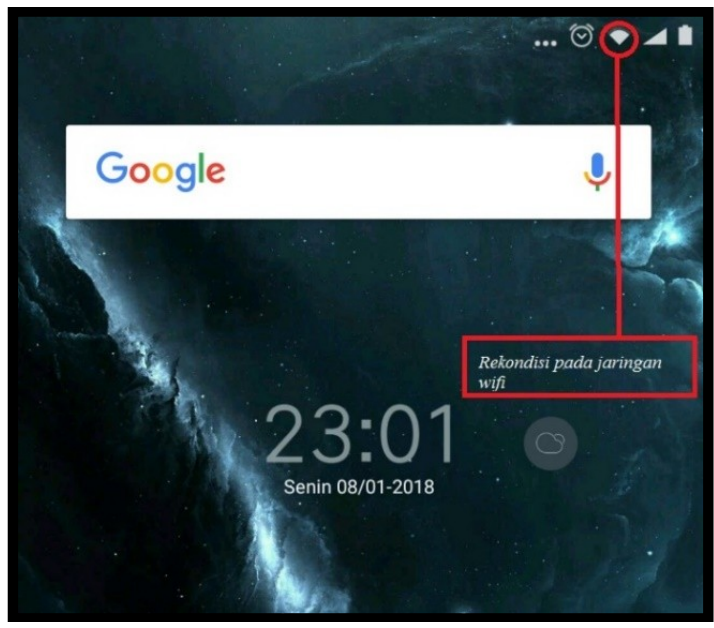

Gambar 4 Rekondisi pada jaringan WIFI

Rekondisi pada Aplikasi Pada smartphone Langkah kedua dari pengujian alat ini adalah melakukan rekondisi pada aplikasi pada Smartphone. Gambar 4.2. menunjukkan rekondisi pada aplikasi pada smartphone. Pada tahap ini bertujuan agar User dapat melihat seberapa kesiapan pada camera pada Smartphone untuk melakukan record Video Set up koneksi IP jarigan WIFI pada aplikasi Smartphone.

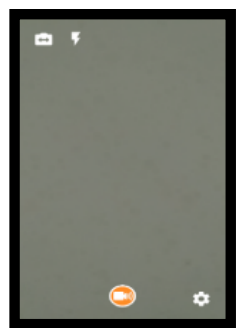

\section{Gambar 5 Rekondisi pada Aplikasi pada Smartphone}

Set up koneksi IP jaringan WIFI pada aplikasi Smartphone

Pada tahap ketiga ini bertujuan dimana User melakukan set up koneksi IP pada jaringan WIFI yang digunakan agar dapat sinkron dengan
Streaming Engine. Gambar 4.3 menunjukkan set up koneksi IP pada jaringan WIFI pada aplikasi Smartphone.

\begin{tabular}{l|c}
\hline CONNECTION SETTINGS & \\
\hline Host Address & $\begin{array}{c}\text { Set up IP WIFI pada } \\
\text { Cmartnhnno }\end{array}$ \\
\hline
\end{tabular}

Gambar 6 set up koneksi IP pada jaringan WIFI pada aplikasi Smartphone

Tahap ini bertujuan agar User dapat sinkron dengan Streaming Engine untuk dapat melakukan inputan record video yang nantinya ditampilkan pada layar LCD. Gambar 4.4. menunjukkan set up koneksi IP jaringan WIFI Streaming Engine

Melakukan proses Vide o Recording

Pada tahap terakhir ini bertujan bahwa User telah siap melakukan Video Recording dengan menggunakan Smartphone. Gambar 4.5. menunjukkan proses Record Video berlangsung.

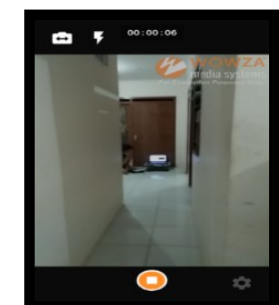

Gambar 7 Proses User Melakukan Video

Recording Menggunakan Smartphone

Hasil pengujian pada variabel pada Provider Pertama dan Kedua dengan format Video Record $480 \times 360$ berdurasi 30 detik

1. Hasil pengujian Delay Menggunakan Provider Pertama dengan menggunakan persamaanm 2.1 menghasilkan Delay terendah adalah $0.003944675 \mathrm{~ms}$, sedangkan Delay tertinggi adalah $0.00429374 \mathrm{~ms}$.

2. Hasil pengujian Troughput Menggunakan Provider Pertama dengan menggunakan persamaan 2.2 menghasilkan Troughput terendah adalah $0.128 \mathrm{Mbps}$, sedangkan Troughput tertinggi adalah $0.178 \mathrm{Mbps}$.

3. Hasil pengujian pengujian Packetloss Menggunakan Provider Pertama dengan menggunakan persamaan 2.3 menghasilkan Packetloss terendah adalah $7.65 \%$, sedangkan Packetloss tertinggi adalah $9.29 \%$. 


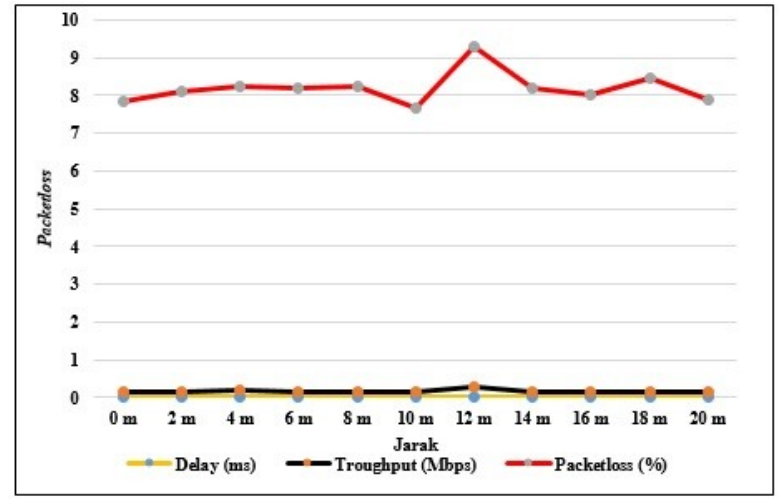

Gambar 8 Hasil Pengujian pada Delay Menggunakan Provider Pertama dalam bentuk grafik pada format $480 \times 360$

4. Hasil pengujian Delay Menggunakan Provider Kedua dengan menggunakan persamaan 2.1 menghasilkan Delay terendah adalah $0.002288135 \mathrm{~ms}$, sedangkan Delay tertinggi adalah $0.00428921 \mathrm{~ms}$.

5. Hasil pengujian Troughput Menggunakan Provider Kedua menggunakan persamaan 2.2 menghasilkan Troughput terendah adalah $0.108 \mathrm{Mbps}$, sedangkan Troughput tertinggi adalah 0.175 Mbps.

6. Hasil pengujian Packetloss Menggunakan Provider Pertama menggunakan persamaan 2.3 menghasilkan Packetloss terendah adalah 7.84 $\%$, sedangkan Packetloss tertinggi adalah 8.45 $\%$.

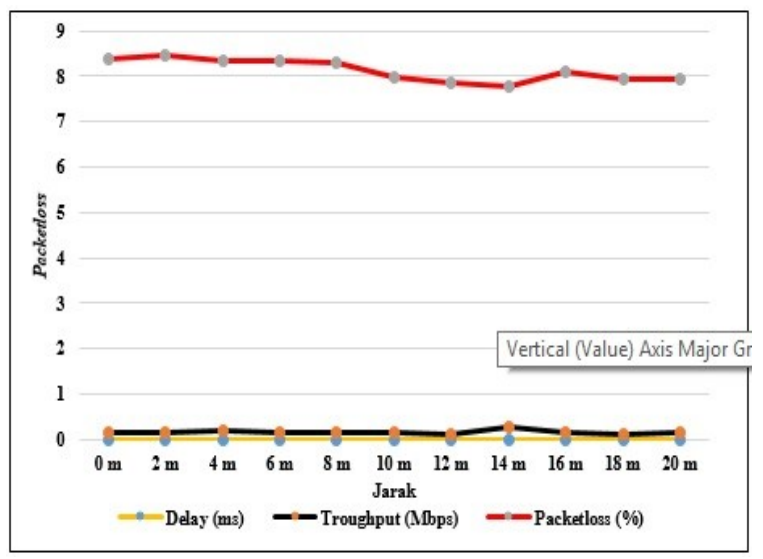

Gambar 9 Hasil Pengujian pada variabel Menggunakan Provider Kedua dalam bentuk grafik pada format $480 \times 360$

Hasil pengujian pada variabel pada Provider Pertama dan Kedua dengan format Video Record 640x360 berdurasi 30 de tik

1. Hasil pengujian Delay Menggunakan Provider Kedua menggunakan persamaan 2.1 menghasilkan Delay terendah adalah $0.004222188 \mathrm{~ms}$, sedangkan Troughput tertinggi adalah $0.004222188 \mathrm{~ms}$.

2. Hasil pengujian Troughput Menggunakan Provider Pertama menggunakan persamaan 2.2 menghasilkan Troughput terendah adalah $0.133 \mathrm{Mbps}$, sedangkan Troughput tertinggi adalah 1.179 Mbps.

3. Hasil pengujian Packetloss Menggunakan Provider Pertama menggunakan persamaan 2.3 menghasilkan Packetloss terendah adalah 6.54 $\%$, sedangkan Packetloss tertinggi adalah 13.6 $\%$.

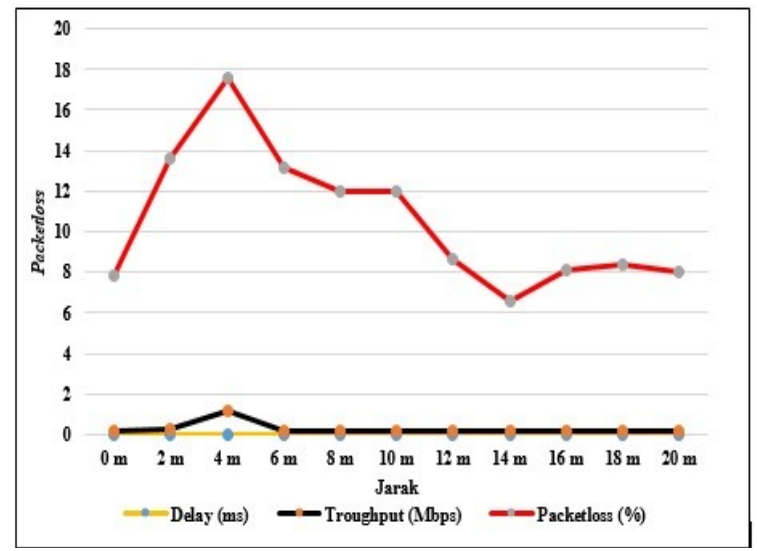

Gambar 10 Hasil Pengujian pada variabel Menggunakan Provider Pertama dalam bentuk grafik pada format $640 \times 360$

4. Hasil pengujian Delay Menggunakan Provider Kedua menggunakan persamaan 2.1 menghasilkan Delay terendah adalah $0.002288135 \mathrm{~ms}$, sedangkan Delay tertinggi adalah $0.0028921 \mathrm{~ms}$.

5. Hasil pengujian Troughput Menggunakan Provider Kedua menggunakan persamaan 2.2 menghasilkan Troughput terendah adalah 1.28 Mbps, sedangkan Troughput tertinggi adalah 0.495 Mbps.

6. Hasil pengujian Packetloss Menggunakan Provider Kedua menggunakan persamaan 2.3 menghasilkan Packetloss terendah adalah 7.49 $\%$, sedangkan Packetloss tertinggi adalah 8.22 $\%$. 


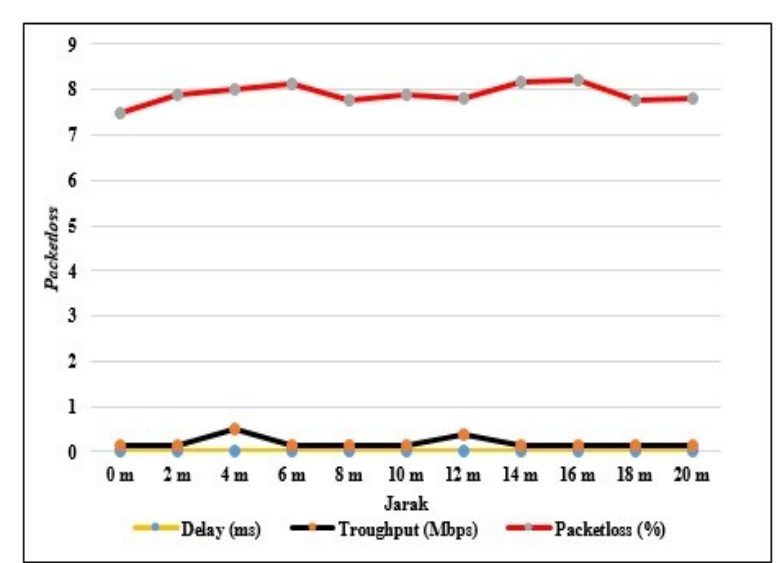

Gambar 11 Hasil Pengujian pada variabel

Menggunakan Provider Kedua dalam bentuk grafik pada format $640 \times 360$

Hasil pengujian pada variabel pada Provider Pertama dan Kedua dengan format Video Record $720 \times 480$ berdurasi 30 de tik

1. Hasil pengujian Delay Menggunakan Provider Kedua menggunakan persamaan 2.1 menghasilkan Delay terendah adalah $0.003865147 \mathrm{~ms}$, sedangkan Delay tertinggi adalah $0.00419375 \mathrm{~ms}$.

2. Hasil pengujian Troughput Menggunakan Provider Pertama menggunakan persamaan 2.2 menghasilkan Troughput terendah adalah $0.130 \mathrm{Mbps}$, sedangkan Troughput tertinggi adalah 0.139 Mbps.

3. Hasil pengujian Packetloss menggunakan Provider Pertama menggunakan persamaan 2.3 menghasilkan packetloss terendah adalah 7.78 $\%$, sedangkan packetloss tertinggi ada lah 8.16

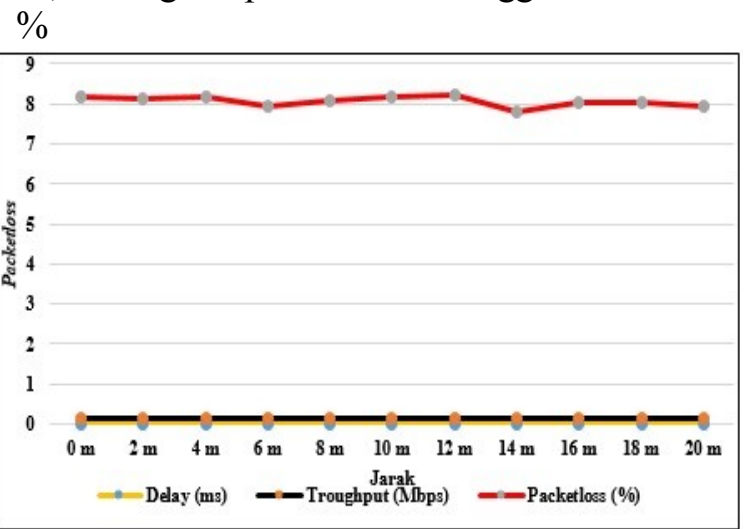

Gambar 4.13. Hasil Pengujian pada variabel Menggunakan Provider Pertama dalam bentuk grafik pada format $720 \times 480$

4. Hasil pengujian Delay menggunakan Provider Kedua menggunakan persamaan 2.1 menghasilkan Delay terendah adalah
$0.005399736 \mathrm{~ms}$, sedangkan Delay tertinggi adalah $0.00446625 \mathrm{~ms}$.

5. Hasil pengujian Troughput menggunakan Provider Kedua menggunakan persamaan 2.2 menghasilkan Troughput terendah adalah 0.126 Mbps, sedangkan Troughput tertinggi adalah 0.172 Mbps.

6. Hasil pengujian Packetloss menggunakan Provider Kedua menggunakan persamaan 2.3 menghasilkan Packetloss terendah adalah 7.56 $\%$, sedangkan Packetloss tertinggi adalah 8.54 $\%$.

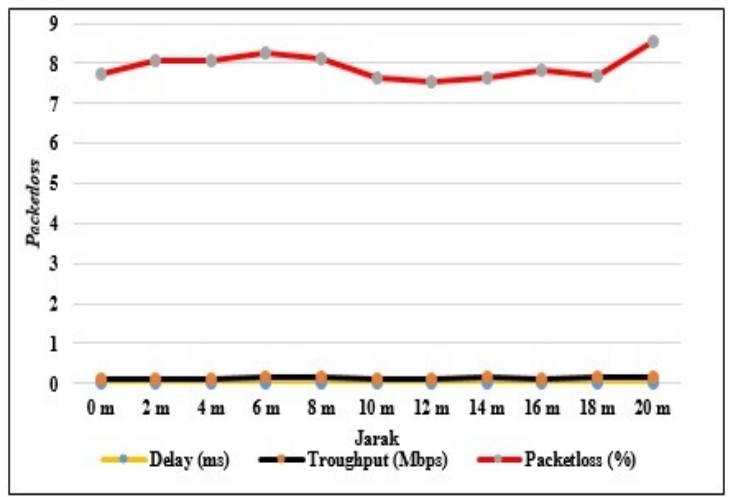

Gambar 4.13. Hasil Pengujian pada variabel Menggunakan Provider Kedua dalam bentuk grafik pada format $720 \times 480$

\section{PENUTUP}

Setelah melakukan tahap perancangan dan pembuatan sistem kerja yang dilanjutkan pada tahap pengujian untuk mendapatkan hasil dan analisa maka dapat diambil kesimpulan, konsistensi jaringan pada provider yang digunakan sanagat berpengaruh pada setiap pengiriman data yang dilakukan oleh user. Hasil dari pengujian yang telah dilakukan adalah sebagai berikut :

1. Pengujian dengan Provider Pertama dan Kedua pada variabel Delay menghasilkan Delay tercepat $0.003944675 \mathrm{~ms}$ dan Delay terlama 0.00429374 ms. pada format Video 480, 640 dan 720 .

2. Pengujian dengan Provider Pertama dan Kedua pada variabel Troughput menghasilkan terendah $0.128 \mathrm{Mbps}$ dan Troughput tertinggi menghasilkan 1.179 Mbps pada format Video 480, 640 dan 720 .

3. Pengujian dengan Provider Pertama dan Kedua pada variabel Packetloss menghasilkan terendah $6.54 \%$ dan Packetloss tertinggi menghasilkan $13.6 \%$ pada format Video 480 , 640 dan 720 .

\section{DAFTAR PUSTAKA}


Unggul Wahyu Tri Purnomo Putro 1, Tri Kuntoro Priyambodo 2, Raden Sumiharto 3 1Prodi Elektronika dan Instrumentasi Jurusan Ilmu Komputer dan Elektronika, FMIPA UGM, Jurusan Ilmu Komputer dan Elektronika, FMIPA UGM, Pengembangan Antarmuka Stasiun Pemantauan Pesawat Tanpa Awak Menggunakan Aplikasi Android, IJEIS, Vol.4, No.2, October 2014, pp. 113 122 ISSN: 2088-3714

Sri Maryati, Bambang Eka Purnama, Pembuatan Video Profil Sekolah Menengah Pertama Negeri 4 Polokarto Kabupaten Sukoharjo Dengan Menggunakan Komputer Multimedia, Journal Speed - Sentra Penelitian Engineering dan Edukasi Volume 5 No 1 - 2013 - ijns.org

Hudaya 1, Gita Indah Hapsari 2, Giva Andriana Mutiara3, Implementasi Live Audio Streaming Menggunakan Raspberry Pi, Program Studi D3 Teknik Komputer Fakultas Ilmu Terapan Universitas Telkom Bandung, Indonesia, Jurnal Teknologi Informasi Vol. 2, No. 3, November 2015, ISSN 20872429

Murtiwiyati, Glenn Lauren, Rancang Bangun Aplikasi Pembelajaran Budaya Indonesia Untuk Anak Sekolah Dasar Berbasis Android, Universitas Gunadarma Depok, Jurnal Ilmiah Komputansi, 2013 Vol. 12 No.2 ISSN : 1412-9434.

Imaduddin al fikri, Darlis herumurti, ridho Rahman H. Aplikasi Navigasi Berbasis Perangkat Bergerak dengan Menggunakan Platform Wikitude Untuk Studi Kasus Lingkungan ITS, Institut Teknologi Sepuluh November Surabaya Jurnal Teknik ITS 2016 Vol. 5 No. 1 ISSN : 2337-3539.

Nur Arifah Syafitri, Sutardi, Anita Puspita Dewi, 2Jurusan Teknik Informatika, Fakultas Teknik, Universitas Halu Oleo, Kendari 3STMIK Catur Sakti, Kendari PENERAPAN METODE WEIGHTED PRODUCT DALAM SISTEM PENDUKUNG KEPUTUSAN PEMILIHAN LAPTOP BERBASIS WEB, semanTIK, Vol.2, No.1, Jan-Jun 2016, pp. 169-176 ISSN : 2502-8928 (Online)

Indrat Susilo, Gesang Kristiyanto Nugraha, Pembangunan Web Server Mengunakan Debian Server Untuk Media Pembelajaran Di Sekolah Menengah Kejuruan (Smk) Negeri 1 Sragen, Indonesian Jurnal on Networking and Security (IJNS)
Enggal Sriwardiningsih, Lydia Angelia, Lisa Aulia, Pengaruh Perilaku Pembelian Mahasiswa Terhadap Keputusan Pembelian Komputer Notebook Di Lingkungan Mahasiswa Binus International, Journal 14 The WINNERS, Vol. 7 No. 1, Maret 2006: 14-25

Nika Irawati 1, Soni Kurniawan 2, 1 Alumni Fakultas Ekonomi UST 2 Fakultas Ekonomi UST, PENGARUH DESAIN DAN KUALITAS PRODUK TERHADAP KEPUASAN KONSUMEN MELALUI KEPUASAN PEMBELIAN LAPTOP ASUS, Jurnal manajemen Dewantara

Radius Tanone, Sushendra Ipol, Fakultas Teknologi Informasi, Universitas Kristen Satya Wacana Jl. Diponegoro 5260,Salatiga, Perancangan dan Implementasi Aplikasi Android Streaming (Studi Kasus FTI Universitas Kristen Satya Wacana Salatiga), Jurnal Teknik Informatika dan Sistem Informasi Volume 1 Nomor 3 Desember 2015, e-ISSN : 2443-2229

I Ketut Agung Enriko Ph.D Student, Departemen Teknik Elektro, Fakultas Teknik, Universitas Indonesia, Depok, Indonesia, Development of Catch-up TV Application on Internet TV Platform for RTSP/RTMP Streaming Protocol, Diterima 28 April 2015, Disetujui 15 Mei, ISSN 2085-4552

Radius Tanone, Sushendra Ipol, Fakultas Teknologi Informasi, Universitas Kristen Satya Wacana, Perancangan dan Implementasi Aplikasi Android Streaming (Studi Kasus FTI Universitas KristenSatya Wacana Salatiga), Jurnal Teknik Informatika dan Sistem InformasiVolume 1 Nomor 3 Desember 2015

Kristian A.Papoto 1, Sherwin R. U. A Sompie, ST., MT 2, Drs. Elia Kendek Allo, Msc 3, 1 Mahasiswa, 2 Pembimbing 1, 3 Pembimbing 2, Jurusan Teknik ElektroFT. UNSRAT, Manado-95115, E-journal Teknik Elektro dan Komputer vol. 5 no. 1, Januari- Maret 2016, ISSN : 2301-8402

Novi Yuliantoa, Fahri Bachruddina, Universitas Mercu Buana, Jl. Meruya Selatan No. 1, DKI Jakarta, Indonesia, Perancangan Sistem Informasi Park, LONTAR KOMPUTER VOL. 7, NO. 3 DESEMBER 2016 p-ISSN 20881541 DOI: 10.24843/LKJITI. 2016. V07. I03. P01 eISSN 2541-5832 
Denny Darlis, Rohmat Tulloh, Sheptian Kurnia Saleh, Program Studi D3 Teknik Telekomunikasi, Fakultas Ilmu Terapan, Universitas Telkom, Sistem Center Periklanan Pameran Di Bandung Berbasis Raspberry Pi Menggunakan Serviio Media Center Systeam For Bandung's Exhibition Advertisin Based Raspberry Pi Jurnal Elektro Telekomunikasi Terapan Desember 2016

Denny Darlis1, Rohmat Tulloh2, Sheptian Kurnia Saleh3 Program Studi D3 Teknik Telekomunikasi, Fakultas Ilmu Terapan, Universitas Telkom Sistem Media Center Periklanan Pameran Di Bandung Berbasis Raspberry Pi Mengunakan Serviio Media Center System For Bandung's Exhibition Advertis in Based Raspberry Using Serviio, Jurnal Elektro Telekomunikasi Terapan Desember 2016 JETT

Aklan Emrul,Muh. Yamin, La Surimi, Jurusan Teknik Informatika, Fakultas Teknik Universitas Halu Oleo, Kendari, Analis is Quality Of Service (Qos) Kinerja Sistem
Hotspot Pada Routerboard Mikrotik 951UI-2HND Pada Jaringan Teknik Informatika, seman TIK, Vol.3, No.2, JulDes 2017, pp. 87-94 ISSN: 2502-8928 (Online)

Hanan Fajar Ramadhan1, Rr. Yuliana R. K. ST., MT.,1, Suwanto Raharjo, S.Si, M.Kom.,Teknik Informatika, FTI, IST AKPRIND, Yogyakarta, Analisi Kinerja Wireless Protocol 802.11 Dan Nstreme Version 2(NV2) Pada Wierless Mikrotik, Jurnal JARKOM Vol. 6 No. 1 Desember 2017 ISSN: 2338-6313Research on the High Robustness JavaEE Enterprise Development Mode Based on Hadoop and Cloud Servers Kun Liu, 2016 4th International Conference on Advances in Social Science, Humanities, and Management (ASSHM 2016) ISBN: 978$1-60595-412-7$

Andi Sunyoto, Dosen STMIK AMIKOM Yugyakarta, AJAX (Asynchronus JavaScript and XML), JURNAL DASI ISSN: $1411-3201 \quad$ Vol. 11 